\title{
COMPARISON OF TWO-LAYER MODEL FOR HYDROGEN AND HELIUM JETS WITH NOTIONAL NOZZLE MODEL PREDICTIONS AND EXPERIMENTAL DATA FOR PRESSURES UP TO 35 MPA
}

\author{
Xuefang $\mathrm{Li}^{1}$, David M. Christopher ${ }^{2}$, Ethan S. Hecht ${ }^{3}$, Isaac W. Ekoto ${ }^{3}$ \\ ${ }^{1}$ Institute of Thermal Science and Technology, Shandong University, Jinan 250061, China, \\ ${ }^{2}$ Thermal Engineering Department, Tsinghua University, Beijing, 100084, China, \\ dmc@tsinghua.edu.cn \\ ${ }^{3}$ Combustion Research Facility, Sandia National Laboratories, Livermore, CA, USA
}

\begin{abstract}
A two-layer, reduced order model of high pressure hydrogen jets was developed which includes partitioning of the flow between the central core jet region leading to the Mach disk and the supersonic slip region around the core. The flow after the Mach disk is subsonic while the flow around the Mach disk is supersonic with a significant amount of entrained air. This flow structure significantly affects the hydrogen concentration profiles downstream. The predictions of this model are compared to previous experimental data for high pressure hydrogen jets up to $20 \mathrm{MPa}$ and to notional nozzle models and CFD models for pressures up to $35 \mathrm{MPa}$ using ideal gas properties. The results show that this reduced order model gives better predictions of the mole fraction distributions than previous models for highly underexpanded jets. The predicted locations of the $4 \%$ lower flammability limit also show that the two-layer model much more accurately predicts the measured locations than the notional nozzle models. The comparisons also show that the CFD model always underpredicts the measured mole fraction concentrations.
\end{abstract}

Keywords: Hydrogen safety; Underexpanded jets; Notional nozzle models; Flow partitioning

\section{NOMENCLATURE}

Roman
$A$
$B$
$c_{\mathrm{p}}$
$d$
$\dot{\mathrm{m}}$
$M$
$P$
$T$
$u$
$\mathrm{~V}$
$X$
$x$
$y^{+}$

area, $\mathrm{m}^{2}$
slip region width, $\mathrm{m}$
specific heat, $\mathrm{W} / \mathrm{kg} \cdot \mathrm{K}$
diameter, $\mathrm{m}$
mass flow rate, $\mathrm{kg} / \mathrm{s}$
Mach number
pressure, $\mathrm{Pa}$
temperature, $\mathrm{K}$
velocity, $\mathrm{m} / \mathrm{s}$
voltage, $\mathrm{v}$
mole fraction
axial location, $\mathrm{m}$
y plus along the wall

Greek
$\gamma$
$\rho$
$\omega$

Subscripts

0

1, 2a, 2b, 3

$\infty$

air

exit

$\mathrm{H} 2$, $\mathrm{He}$

Mach

slip specific heat ratio

density, $\mathrm{kg} / \mathrm{m}^{3}$

mass fraction

stagnation

state points

ambient

air

nozzle exit

hydrogen, helium

Mach disk

slip region

\subsection{INTRODUCTION}

Hydrogen fueled cars are being developed in many countries to address the pollution problems caused by fossil-fueled cars and to provide viable alternatives for when fossil fuels are no longer available. Thus, hydrogen will be an important part of the energy mix of future low carbon societies $[1,2]$. One fueling option for hydrogen fueled vehicles is to have on-board hydrogen storage tanks at pressures up to $70 \mathrm{MPa}$ that hold about $5 \mathrm{~kg}$ of hydrogen, giving vehicles a range that is comparable to current fossil-fueled cars. The fueling stations store the hydrogen at about $35 \mathrm{MPa}$ and then further compress the hydrogen to fuel the vehicles. The vehicles and fueling stations should be designed so that their 
safety levels are equal to or better than for current fossil-fueled vehicles and stations. Thus, the safety issues of leaks from these high pressure systems must be addressed when designing these systems.

Hydrogen leaks can be classified as low pressure leaks, where the exit flow is not choked, or high pressure leaks, where the flow is choked at the orifice, forming an underexpanded jet. The flow fields and gas distributions from low pressure leaks can be modeled using an integral similarity model [3-5]. Most experimental studies of jet flows have used relatively small Froude numbers due to experimental size and cost limitations, with only four studies having pressures above $10 \mathrm{MPa}$ [6-9] with most of their measurements at hydrogen mole concentrations below $10 \%$ where all the models agree within the measurement accuracy.

Hydrogen releases from high pressure tanks result in high pressure jets with very complex shockwave structures $[10,11]$ until the flow expands to a subsonic jet that disperses the hydrogen into the air. The central part of the jet accelerates up to the Mach disk where the flow becomes subsonic. However, a slip region forms outside this central core with numerous expansion waves. The supersonic flow in the slip region interacts with the flow through the Mach disk downstream of the Mach disk, where the hydrogen and air continue to mix. The current study presents experimental and numerical studies of the release and dispersion of hydrogen into air with a two-region reduced order model that partitions the flows in the core region and in the slip region unlike current models that only have one flow region. This model can be used to rapidly and more accurately model high pressure, underexpanded jet flows.

One key goal is to identify the flammability limit when hydrogen accidently leaks from a system. The lower flammability limit for hydrogen in air is a $4 \%$ mole fraction; thus, designers need to be able to quickly identify the location of the $4 \%$ hydrogen mole fraction contour. The flammability of a hydrogen-air cloud is not only a function of the hydrogen concentration at the lower flammability limit, but is also a function of the hydrogen distribution within the cloud, the flow field and the turbulence within the cloud. Thus, ignition will be strongly affected by the external flow conditions around the jet and the confinement of the hydrogen-air cloud. Therefore, computational models are needed that can accurately predict the flow, temperature, concentration and turbulence fields during the release and dispersion of the hydrogen [12] and these models must be verified against experimental data.

There are few numerical studies of high pressure highly under-expanded hydrogen jets into the atmosphere because the hydrogen properties make the numerical calculations very unstable and slow [13]. Chin et al. [14] modeled the flow from a $353 \mathrm{kPa}$ tank and found higher spreading ratios than seen experimentally. Papanikolaou and Baraldi [15] predicted the hydrogen jet flow and dispersion for a $9.8 \mathrm{MPa}$ tank pressure. Xu et al. [13] divided the analysis for a $20 \mathrm{MPa}$ tank pressure into two problems with large eddy simulations (LES) near the exit and a second finite-difference analysis downstream. They noted that there is a lack of good experimental data available at high pressures to validate the numerical results. Angers et al. [16] numerical simulated hydrogen releases from a 70 $\mathrm{MPa}$ tank for very short times and also noted the lack of high pressure experimental data for validation. Others have presented limited results for flow fields very near the nozzle or for short times due to stability and time limitations for high Mach number flows [16-18]. The accuracy of CFD model predictions is also limited by the ability of the turbulence model to predict these flows $[15,19]$. Many studies have used the standard k- $\varepsilon$ turbulence models, while others have used more advanced models [20] or LES [18]. More comparisons with experimental data are needed to verify the accuracy of the turbulent models.

The difficulties and computational expense of CFD simulations of the near-orifice region has led to a simplified approach based on the notional nozzle concept using an effective nozzle diameter [4, 2126]. This method does not model the complex shock structure, but rather the release is assumed to start with a jet flow from a pseudo nozzle orifice [21] assuming that all of the flow passes through this notional nozzle with uniform velocity and concentration profiles. This nozzle approach has been widely used even though the assumptions, such as neglecting air entrainment into the jet and 
uncertainties about the temperatures downstream [13], affect prediction accuracy [18]. These models also do not account for the very nonuniform jet velocity profile due to the partitioning of the flow between the central core that passes through the Mach disk and the flow in the supersonic slip region [27]. HySafe [28] recommended that such approaches be further validated for a wide range of stagnation pressures. Li and Christopher [27] and $\mathrm{Li}$ et al. [29] presented results for jet flows for pressures up to $70 \mathrm{MPa}$ that showed that much more than half of the hydrogen flows into the supersonic slip region with significant air entrainment, so the notional nozzle model cannot accurately represent the flow fields. Tchouvelev [30] compared CFD predictions to notional nozzle results for a hydrogen release from a $43 \mathrm{MPa}$ tank to show that the notional nozzle results were significantly different from the CFD model results. They concluded that the notional nozzle approach needs further improvements and the CFD models need to be validated with more experimental data at higher pressures. Thus, a two zone partitioning model has been developed to more accurately represent the flow partitioning into the central core region that passes through the Mach disk and the flow in the barrel shock region.

There are only a few experimental studies of very high pressure under-expanded jets. Crist et al. [10] measured the Mach disk locations at pressures up to $100 \mathrm{MPa}$ for various gases. Birch et al. [21] compared the Mach disk locations for ethylene and natural gas at pressures up to 7.1 MPa with their notional nozzle model. Birch et al. [22] then measured velocities along the centerline in high pressure air jets for pressures up to $8 \mathrm{MPa}$. Inman et al. [11] used a planar laser induced fluorescence (PLIF) system to observe the flow structures in underexpanded jets. Glotov [31] used the shadowgraph technique to observe the flow structures in underexpanded jets. Yuceil et al. [32] measured the velocities near the nozzle exit of underexpanded jets and the Mach disk location using Schlieren visualization. Ruggles and Ekoto [33] used Schlieren photography to measure the jet shock structure for a 10:1 pressure ratio and Planar Laser Rayleigh Scatter imaging to measure hydrogen mole fractions but the data did not agree well with notional nozzle predictions. Veser et al. [34] and Kuznetsov et al. [35] measured hydrogen concentrations in underexpanded jets for pressures of 10 $\mathrm{MPa}$. Li et al. [36] measured the Mach disk locations and sizes and the concentration distributions for pressures up to $6 \mathrm{MPa}$.

This paper presents a two-layer reduced order model for highly underexpanded jets that separates the flow into the flow through the Mach disk region and the flow in the supersonic slip region to more accurately represent the actual flow structure. The predictions are then compared with experimental data and previous notional nozzle model predictions and CFD model predictions. The two-layer model is shown to more accurately predict the species distributions downstream.

\subsection{EXPERIMENTAL SYSTEM}

The experiment was conducted inside a large room at constant temperature to eliminate the influence of wind and temperature fluctuations. The inner dimensions of the room were $15 \mathrm{~m}$ long, $10 \mathrm{~m}$ wide and $3.5 \mathrm{~m}$ high, so that the jet impinging on the opposite wall was assumed to have negligible effect on the jet flow. The experiment setup is illustrated in Figure 1. 


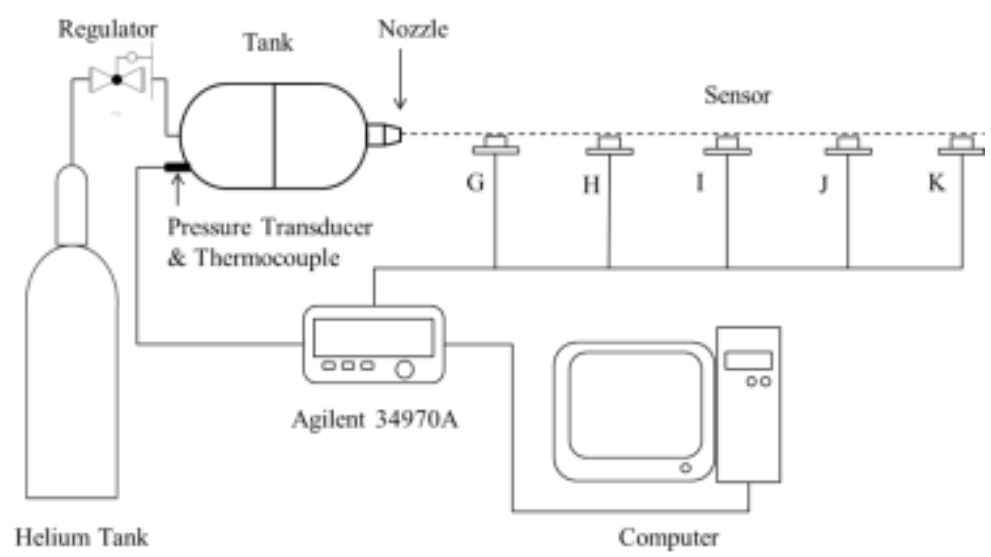

Figure 1. Schematic of the experimental setup.

Helium was used as a substitute of hydrogen for safety reasons. The cylindrical tank was made of 8 $\mathrm{mm}$ thick stainless steel with an inner volume of $3.5 \mathrm{~L}$ and a maximum operating pressure of 150 bar. A nozzle was mounted on the front of the tank with a ball valve to control the flow. The nozzle diameter was $2.0 \mathrm{~mm}$. A pressure transducer and a PT100 thermocouple were mounted on the back end of the chamber to monitor the pressure and temperature during the experiment. A $40 \mathrm{~L}$ tank filled with helium to an initial pressure of 135 bar was used to feed the tank through a regulator to control the charging pressure as well as to maintain a steady pressure inside the leak chamber. Five XENTCG3880Pt type sensors (thermal conductivity gauges), indicated by $\mathrm{G}$ to $\mathrm{K}$ in Figure 1, were located at $200 \mathrm{~mm}, 500 \mathrm{~mm}, 800 \mathrm{~mm}, 1100 \mathrm{~mm}$ and $1700 \mathrm{~mm}$ from the nozzle exit to measure the jet centerline mole fractions. The output voltage signals were recorded by an Agilent 34970A data acquisition unit and then converted to the corresponding mole fractions in Excel.

The thermal conductivity gauges were used to calculate the gas concentrations in the helium-air mixture by measuring the thermal conductivity of the gas mixture. Given the significant difference between the thermal conductivity of helium $(0.15 \mathrm{~W} / \mathrm{m} \cdot \mathrm{K})$ and air $(0.026 \mathrm{~W} / \mathrm{m} \cdot \mathrm{K})$, the thermal conductivity gauges were particularly suitable for the helium concentration measurements in air. The XEN-TCG3880Pt sensors were calibrated in place by flooding them with gases of known helium concentrations. Three bottles with different gas concentrations were used with known helium mole fractions of $10 \%, 40.2 \%$ and $99.999 \%$, so 4 concentration points were obtained with pure air as the $0 \%$ helium mole fraction. A typical calibration curve is shown in Figure 2. Each sensor was calibrated with separate calibration functions that were then used to convert the voltage readings to concentrations.

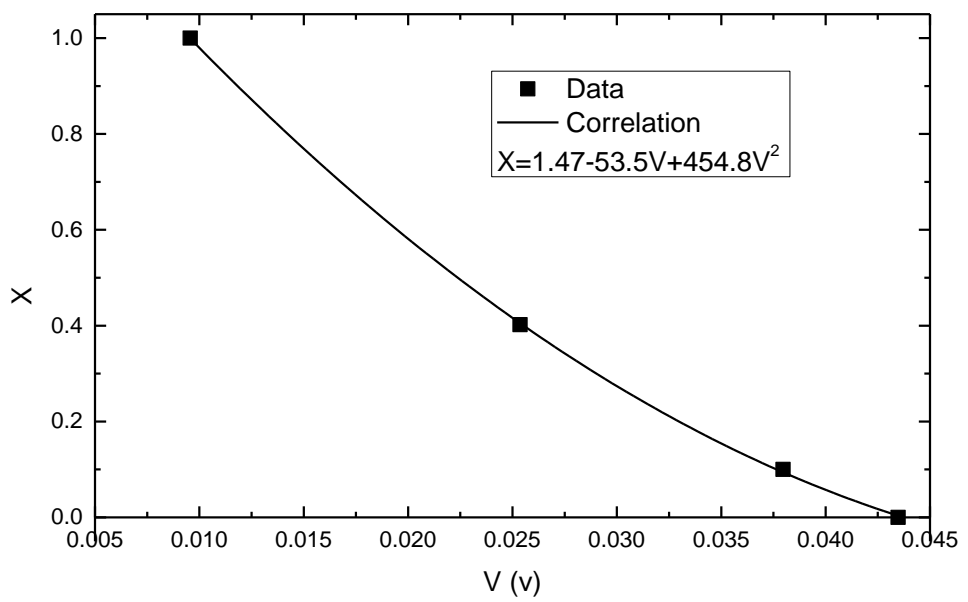

Figure 2. Typical calibration curve for a XEN-TCG3880Pt sensor for helium-air mixtures. 


\subsection{NUMERICAL MODELS}

The CFD model solved the Reynolds averaged Navier-Stokes (RANS) equations for steady-state, twodimensional axisymmetric turbulent flow with the energy equation. The mass transfer equation was solved, the standard k- $\varepsilon$ turbulence model was used, and the standard Fluent wall functions (although there were no walls in some models) were used. The density was modelled as an ideal gas. The computational domain (for notional nozzle models and the two-layer partitioning model) was a rectangle (cylinder in the axisymmetric coordinate system) with an outer radius of $0.8 \mathrm{~m}$ which is much greater than the actual or notional nozzle radii and a length of $5 \mathrm{~m}$. This long length was necessary to allow the hydrogen concentration to decay to less than the lower flammability limit of $4 \%$ mole fraction. However, as the pressure ratios are quite large (26 to 200) and high velocity jets are expected, the buoyancy effects in the range of calculation are negligible. The equations were solved using the density solver in Fluent 14. The outer surface and the downstream exit were set as pressure boundary conditions. The portion of the left (inlet) end outside of the nozzle (or notional nozzle) was set as a mass inlet boundary condition with a very small flow rate of air that created velocities several orders of magnitude less than the nozzle (or notional nozzle) inlet velocity as has been done previously [4]. This prevented the flow from backing up along the wall and the hydrogen from expanding out to fill the entire region. A 10 times greater air mass flow rate at this left edge did not change the concentration profiles. The hydrogen inlet models are discussed below.

\subsection{Notional nozzle models}

Notional nozzle models have been developed by Birch et al. [21] based on data for underexpanded natural gas jets, Birch et al. [22] based on data for underexpanded air jets, Ewan and Moodie [23] also based on data for underexpanded air jets, Yuceil and Otugen [24] also based on data for underexpanded air jets and Molkov et al. [25]. These all predict a notional nozzle size and flow velocity through the notional nozzle region with the two models by Birch et al. [22] assuming that the gas temperature at the notional nozzle is $300 \mathrm{~K}$, Ewan and Moodie assuming that the gas temperature at the notional nozzle is $250 \mathrm{~K}$, and Yuceil and Otugen calculating the gas temperature at the notional nozzle. The model by Molkov et al. [25] assumed that the velocity after the notional nozzle exit was at the sonic speed and used the Abel-Noble real gas properties. Li et al. [36] compared the jet similarity model for the downstream flow field developed by Houf and Schefer [37] that uses assumed Gaussian hydrogen concentration and velocity profiles to a large amount of hydrogen concentration profile data at pressures up to $6 \mathrm{MPa}$ to validate an equivalent source model for highly underexpanded hydrogen jets that is similar to a notional nozzle model. The conditions at the notional nozzle were then used as the boundary conditions for CFD models of the downstream flow. Three models were used with from 41,000 to 88,000 elements with all three meshes giving nearly the same results. The results reported here are for a mesh with 57,000 elements and 20 elements along the inlet. All the calculations used Fluent 14 with ideal gas properties. The calculations had to use relatively small Courant numbers of around 1 for stability, so convergence of the flow and concentrations fields far downstream was very slow. Since different pressure ratios and different notional nozzle models gave different notional nozzle diameters, a new mesh was built for each case but with the same numbers of elements in each of the three size meshes for the different notional nozzle models and different pressure ratios.

\subsection{Two-layer partitioning model}

A typical underexpanded jet structure is illustrated in Figure 3. The stagnant hydrogen gas in the chamber is at state 0 and then accelerates to the nozzle exit (state 1) where the flow is choked. Part of the hydrogen gas remains in the core flow region and expands to supersonic flow with the highest Mach number just upstream of the Mach disk (state 2a). The gas then passes through the normal shock where the gas pressure suddenly increases to atmospheric pressure, the temperature approaches ambient temperature and the velocity decreases to a subsonic velocity (state $2 \mathrm{~b}$ ). Meanwhile, the rest of the hydrogen gas flows into the slip region with air entrained into the flow (state 3) with this slip flow region then bypassing the Mach disk at higher velocities than at state $2 \mathrm{~b}$. The flow is assumed to isentropically expand from state 1 to state 2 and then to state 3 . The air entrainment is assumed to only 
occur in the slip region, so that the flow through the Mach disk is pure hydrogen. The pressure in the slip region is approximately atmospheric. To simplify the model, the velocity at state 3 is assumed to be uniform.

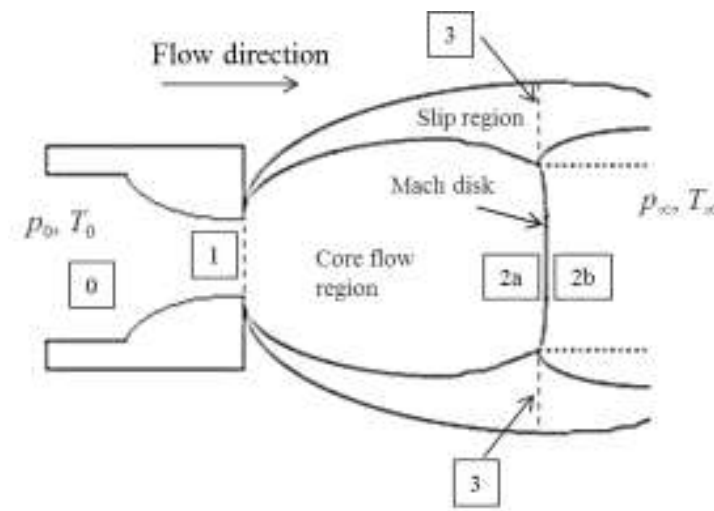

Figure 3. Structure of an underexpanded jet.

Since the flow is choked at the nozzle exit, the flow parameters at state $1 \mathrm{can}$ be calculated using the choked flow equations for ideal gases. The maximum Mach number in the core flow region will occur at the end of the expansion process, state 2a. Assuming isentropic flow, the pressure at state 2a is [38]:

$$
\frac{P_{0}}{P_{2 a}}=\left(1+\frac{\gamma-1}{2} M^{2}\right)^{\frac{\gamma}{\gamma-1}}
$$

The pressure after the Mach disk is assumed to be atmospheric and the pressure jump across the normal shock wave is [39]:

$$
\frac{P_{2 a}}{P_{\infty}}=\frac{\gamma+1}{2 \gamma M^{2}-(\gamma-1)}
$$

These can be combined to give the maximum Mach number, $\mathrm{M}_{2 \mathrm{a}}$, as:

$$
\frac{p_{0}}{p_{\infty}}=\frac{\left(1+\frac{\gamma-1}{2} M_{2 a}^{2}\right)^{\gamma /(\gamma-1)}}{\frac{2 \gamma}{\gamma+1} M_{2 a}^{2}-\frac{\gamma-1}{\gamma+1}}
$$

Then, $M_{2 \mathrm{~b}}$ can be calculated using the normal shock correlation [39]:

$$
M_{2 b}=\left(\frac{2+(\gamma-1) M_{2 a}^{2}}{2 \gamma M_{2 a}^{2}-(\gamma-1)}\right)^{1 / 2} .
$$

The areas of regions 2 and 3 are defined based on two empirical equations for the Mach disk diameter and the slip region thickness [36]:

$$
\begin{gathered}
d_{\text {Mach }} / d_{\text {exit }}=0.35 \sqrt{p_{0} / p_{\infty}}, \\
B_{\text {slip }} / d_{\text {exit }}=0.30 \sqrt{p_{0} / p_{\infty}} .
\end{gathered}
$$

These equations were developed from data for a large number of underexpanded hydrogen jets for pressures up to $6 \mathrm{MPa}$ with the assumption that these correlations can be extended to higher pressures. The cross-sectional area of the slip region is then: 


$$
A_{3}=\pi\left(\frac{d_{\text {Mach }}}{2}+B_{\text {slip }}\right)^{2}-A_{2}
$$

The conservation equations for mass, momentum and energy from the nozzle exit to state $2 \mathrm{~b}$ and state 3 can be written as:

$$
\begin{gathered}
\dot{m}_{1}=\dot{m}_{2}+\left(1-\omega_{\text {air }}\right) \rho_{3} A_{3} u_{3}, \\
p_{1} A_{1}+\dot{m}_{1} u_{1}=p_{2 b} A_{1}+\dot{m}_{2} u_{2 b}+\rho_{3} A_{3} u_{3}^{2}, \\
\dot{m}_{1}\left(c_{p, \mathrm{H} 2} T_{1}+\frac{u_{1}^{2}}{2}\right)=\dot{m}_{2}\left(c_{p, \mathrm{H} 2} T_{2 b}+\frac{u_{2 b}^{2}}{2}\right)+\rho_{3} A_{3} u_{3}\left(c_{p, 3} T_{3}+\frac{u_{3}^{2}}{2}-\omega_{\text {air }} c_{p, \text { air }} T_{\infty}\right) .
\end{gathered}
$$

where $c_{\mathrm{p}, 3}$ is the mixture specific heat capacity calculated using the binary gas mixing law.

The conservation equations, Eqs. (8) to (10), and the equation of state can be solved to determine the velocity, $u_{3}$, temperature, $T_{3}$, mixture density, $\rho_{3}$, and air mass fraction, $\omega_{\text {air }}$ at state 3 . The temperatures, flowrates, and areas at states $2 \mathrm{~b}$ and 3 were then used as the inlet boundary conditions to the CFD model. The results were evaluated on three rectangular meshes with 27,900, 52,500 and 101,000 elements with similar results among all three meshes for lower pressures and far downstream and similar results for the larger two meshes for higher pressures. The results presented here are for the mesh with 52,500 elements with Fluent 14 used to solve the equations with ideal gas properties.

\subsection{Full CFD solution}

In the full CFD simulation, the nozzle and expansion region were also meshed and modeled. Like the experiments, the nozzle was shaped as an ASME long radius nozzle to smooth the flow exiting the 2 $\mathrm{mm}$ orifice. The value of $\mathrm{y}^{+}$along the nozzle wall varied greatly depending on the upstream stagnation pressure from approximately 50 to 500. The calculations did not lead to a steady-state solution due to vortices being shed from around the nozzle exit, so the results presented here are averages over many $(5,000$ to 10,000$)$ iterations. Other wall functions and turbulence models were used with similar results. The one-equation Spalart-Allmaras model was also used with the results converging very well, but the model does not perform well in shear flows. In this application the predicted concentrations were much lower than those predicted by the other models and the experimental data so the SpalartAllmaras model predictions are not reported here. The meshes for the full CFD solutions had 302,000, 316,000 and 418,000 elements. All the calculations used Fluent 14 with ideal gas properties. The results were similar with differences in the hydrogen molar concentrations at various monitoring points of 2-3\%. The results presented here are all for the largest mesh with 20 elements along the inlet. The models used a constant mass diffusivity with molar concentrations calculated using the mass diffusivity determined from kinetic theory being about $2 \%$ higher very near the nozzle exit and much closer to the constant mass diffusivity results far downstream. The molar concentrations are expected to be higher, especially near the nozzle, when using kinetic theory since the mass diffusivity decreases with temperature so the diffusion would be much lower in the near-field colder part of the jet. Thus, the constant mass diffusivity was used for the results presented here.

\subsection{RESULTS}

The CFD model results for the flow and concentration fields from the notional nozzle models and the two-layer, reduced order model are compared against the full CFD models for pressures of $2.6 \mathrm{MPa}$, $10 \mathrm{MPa}, 20 \mathrm{MPa}$ and $35 \mathrm{MPa}$. Experimental data are also used to validate the model for pressures up to $20 \mathrm{MPa}$. The centerline molar concentration for a $2.6 \mathrm{MPa}$ stagnation pressure helium jet from a 2 $\mathrm{mm}$ diameter nozzle is shown in Figure 4. The predictions of the various models are compared with data from the present study with all 5 data points within $1.7 \mathrm{~m}$ of the nozzle where the model predictions have the greatest differences. The inset shows all the results for a small part of the graph 
from $0.4 \mathrm{~m}$ to $1.8 \mathrm{~m}$. The mole fraction predictions using the four notional nozzle models are all above the data, with the two-region, reduced order model and the full CFD model both more accurately predicting the experimental data. The Ewan and Moodie [23] model predicts the highest centerline helium mole fractions, followed by the Yuceil and Otugen [24] model, the earlier Birch et al. [21] model and finally the later Birch et al. [22] model. These four notional model predictions are all quite similar with the two-layer, reduced order model performing better than even the best notional nozzle model. The full CFD model given by the solid green line gives the best predictions. For very short distances from the Mach disk $(x<0.1 \mathrm{~m})$, the two-layer, reduced order model is expected to better predict the extended high concentration region along the centerline that must develop just after the Mach disk since there is no entrainment into the gas flowing through the Mach disk.

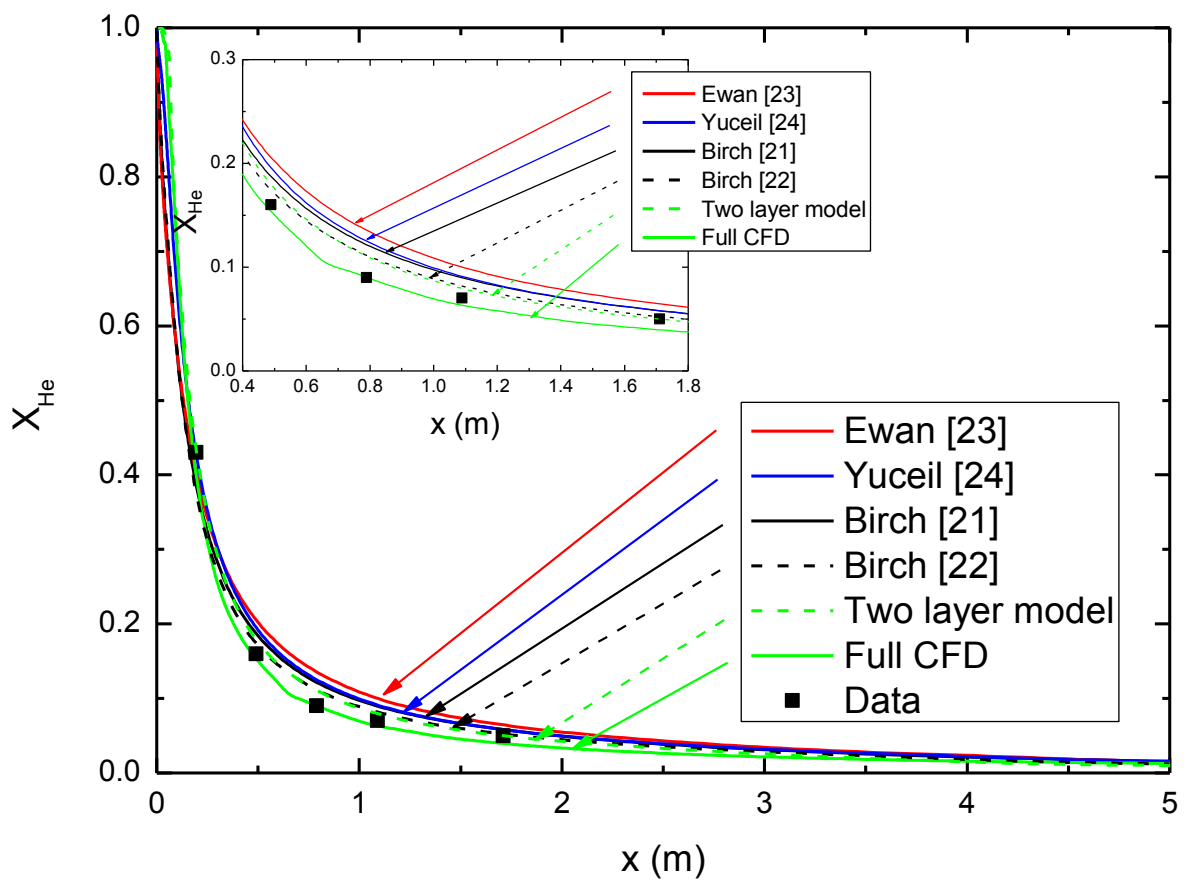

Figure 4. Helium mole fraction centerline concentration variations for $2.6 \mathrm{MPa}$ tank pressure and a 2 $\mathrm{mm}$ diameter orifice.

The centerline molar concentrations predicted by the various models for a $10 \mathrm{MPa}$ stagnation pressure hydrogen jet through a $1 \mathrm{~mm}$ diameter nozzle are shown in Figure 5. The numerical results are compared with data from Han et al. [6] who obtained a large amount of data for a variety of conditions, but only the data points at $1 \mathrm{~m}, 3 \mathrm{~m}$, and $5 \mathrm{~m}$ can be seen in the figure with the data point 1 $\mathrm{m}$ from the nozzle exit being in the region of most interest where the models have greater variations in their predictions. The Ewan and Moodie [23] model again predicts the highest centerline mole fractions with the Molkov et al. [25] model giving almost the same results, followed by the Yuceil and Otugen [24] model, the earlier Birch et al. [21] model, with the later Birch et al. [22] model giving concentration predictions most similar to the data. The Yuceil and Otugen model does not give better predictions than the Birch et al. [22] model, even though it includes an equation to predict the flow temperature at the notional nozzle. The two-layer model accurately reproduces the data, with the full CFD model predicting mole fractions slightly below the data. The full CFD model used by Han et al. [6] also slightly under-predicted their data. This indicates excessive diffusion in the numerical model which is likely due to the turbulence model, but could also be due to an inappropriate value of the turbulent Schmidt number that is assumed to be 0.7 [40]. A larger turbulent Schmidt number would reduce the hydrogen diffusion and increase the centerline concentrations. All of the model predictions converge and agree with the data beyond $3 \mathrm{~m}$ from the nozzle. 


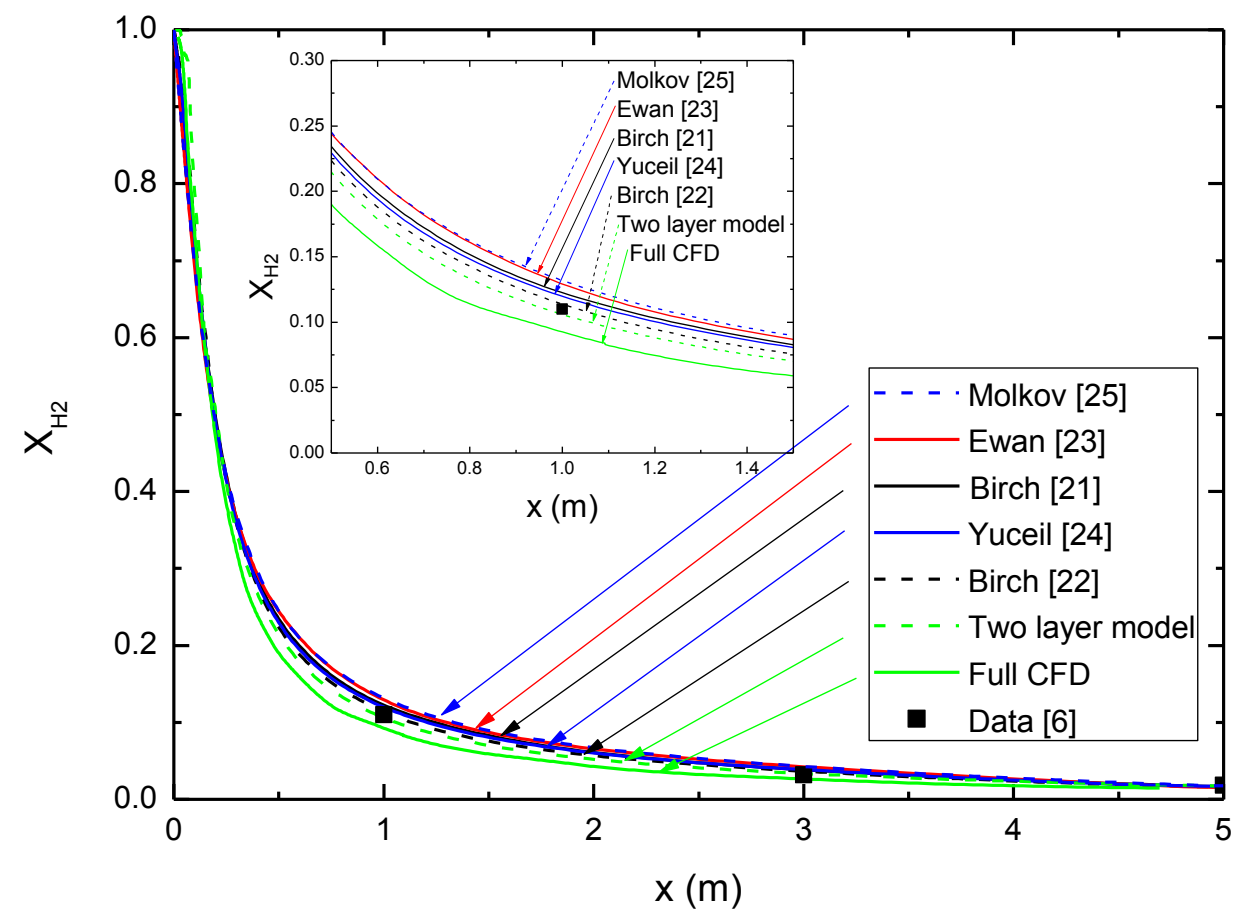

Figure 5. Hydrogen mole fraction centerline concentration variations for $10 \mathrm{MPa}$ tank pressure and a 1 $\mathrm{mm}$ diameter orifice.

The molar concentrations along the centerline predicted by the various models for a $20 \mathrm{MPa}$ stagnation pressure hydrogen jet issuing from a $1 \mathrm{~mm}$ diameter nozzle are compared to experimental data [6] in Figure 6. The notional nozzle predictions again have only slight differences, with the Ewan and Moodie [23] model giving the highest mole fraction predictions and the Birch et al. [22] model giving the lowest predictions that are closest to the data of the notional nozzle models. The Molkov et al. [25] model gives better results at this higher pressure since it is based on real gas properties. The two-layer model once again very closely agrees with the experimental data at both $\mathrm{x}=1 \mathrm{~m}$ and $\mathrm{x}=3$ $\mathrm{m}$; thus, the two-layer model appears to be more effective than previous notional nozzle approaches at higher pressures. The full CFD model is again slightly below the data indicating too much dispersion or air entrainment into the jet. All the models agree with the experimental data at $\mathrm{x}=5 \mathrm{~m}$. These calculations all used ideal gas properties in the CFD models. Calculations with the Peng-Robison real gas model gave very slightly lower concentrations with the two layer model still giving the best agreement with the experimental data.

The relative errors of the predictions relative to the measured data are shown in Table 1 for the 5 notional nozzle models, the two layer model and the full CFD solution. The errors are reported as the average relative errors for all the data points shown in Figure 4 - Figure 6. The two layer model most accurately predicts the data except for the $2.6 \mathrm{MPa}$ helium jet and performs especially well at the higher pressures. The later Birch et al. [22] notional nozzle model gives better results than the other notional nozzle models except for the highest pressure. The full CFD model is not better than the notional nozzle models, again because the turbulent Schmidt number in the turbulence models is too small.

Table 1. Average relative errors for each model relative to the measured data.

\begin{tabular}{llllllll}
\hline P & Ewan [23] & Yuceil [24] & Birch [21] & Birch [22] & Molkov [25] & $\begin{array}{c}\text { Two layer } \\
\text { Model }\end{array}$ & Full CFD \\
\hline
\end{tabular}




\begin{tabular}{lccccccc}
\hline $2.6 \mathrm{MPa}$ & $31 \%$ & $22 \%$ & $21 \%$ & $13 \%$ & & $10 \%$ & $8 \%$ \\
$10 \mathrm{MPa}$ & $22 \%$ & $12 \%$ & $13 \%$ & $9 \%$ & $19 \%$ & $4 \%$ & $19 \%$ \\
$20 \mathrm{MPa}$ & $23 \%$ & $11 \%$ & $19 \%$ & $9 \%$ & $17 \%$ & $4 \%$ & $14 \%$ \\
\hline
\end{tabular}

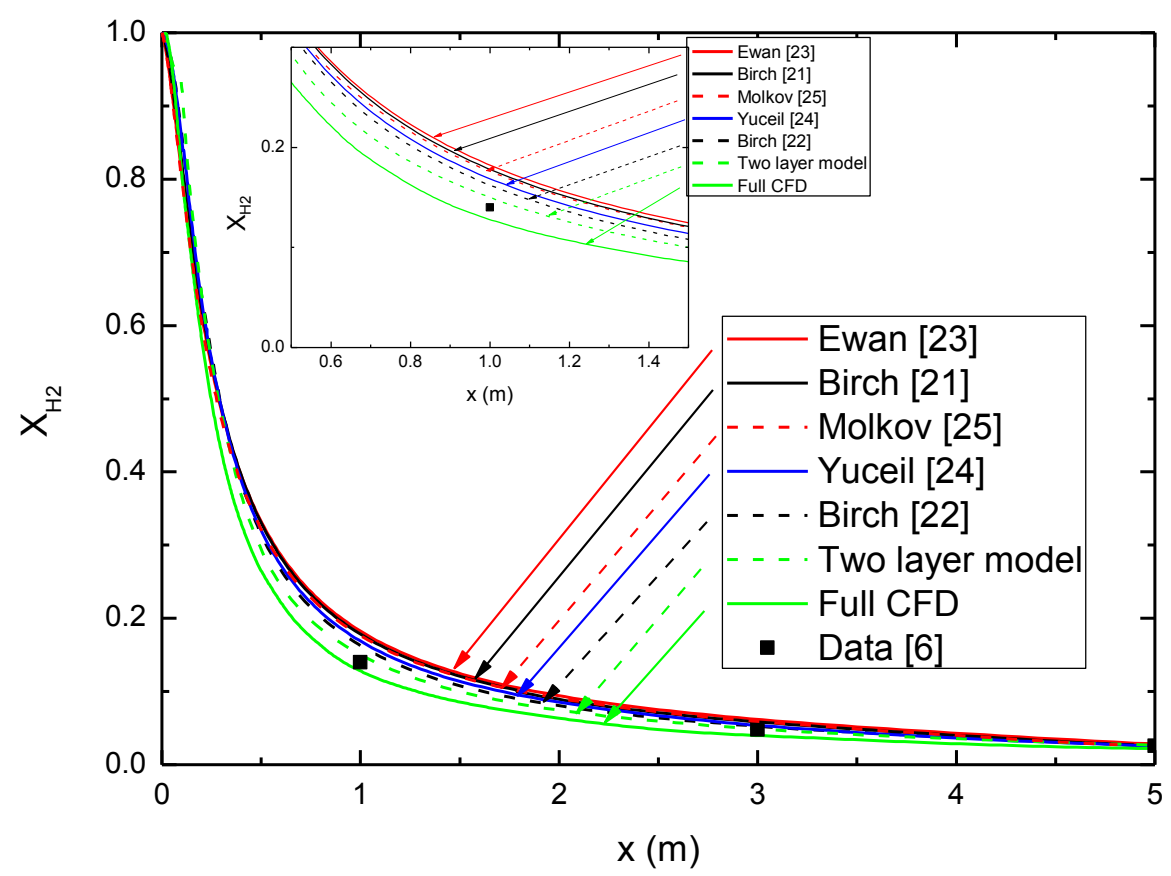

Figure 6. Hydrogen mole fraction centerline concentration variations for $20 \mathrm{MPa}$ tank pressure and a 1 $\mathrm{mm}$ diameter orifice.

The molar concentrations along the centerline predicted by the various models for a $35 \mathrm{MPa}$ stagnation pressure hydrogen jet issuing from a $1 \mathrm{~mm}$ diameter nozzle are shown in Figure 7. The Ewan and Moodie [23] model again leads to the highest concentration predictions with very similar predictions to the older Birch et al. [21] model. The Yuceil and Otugen [24] and Molkov et al. [25] predictions are almost the same, but slightly higher than the Birch et al. [22] predictions. The twolayer model is then slightly lower with the full CFD model also lower as for the lower pressures. 


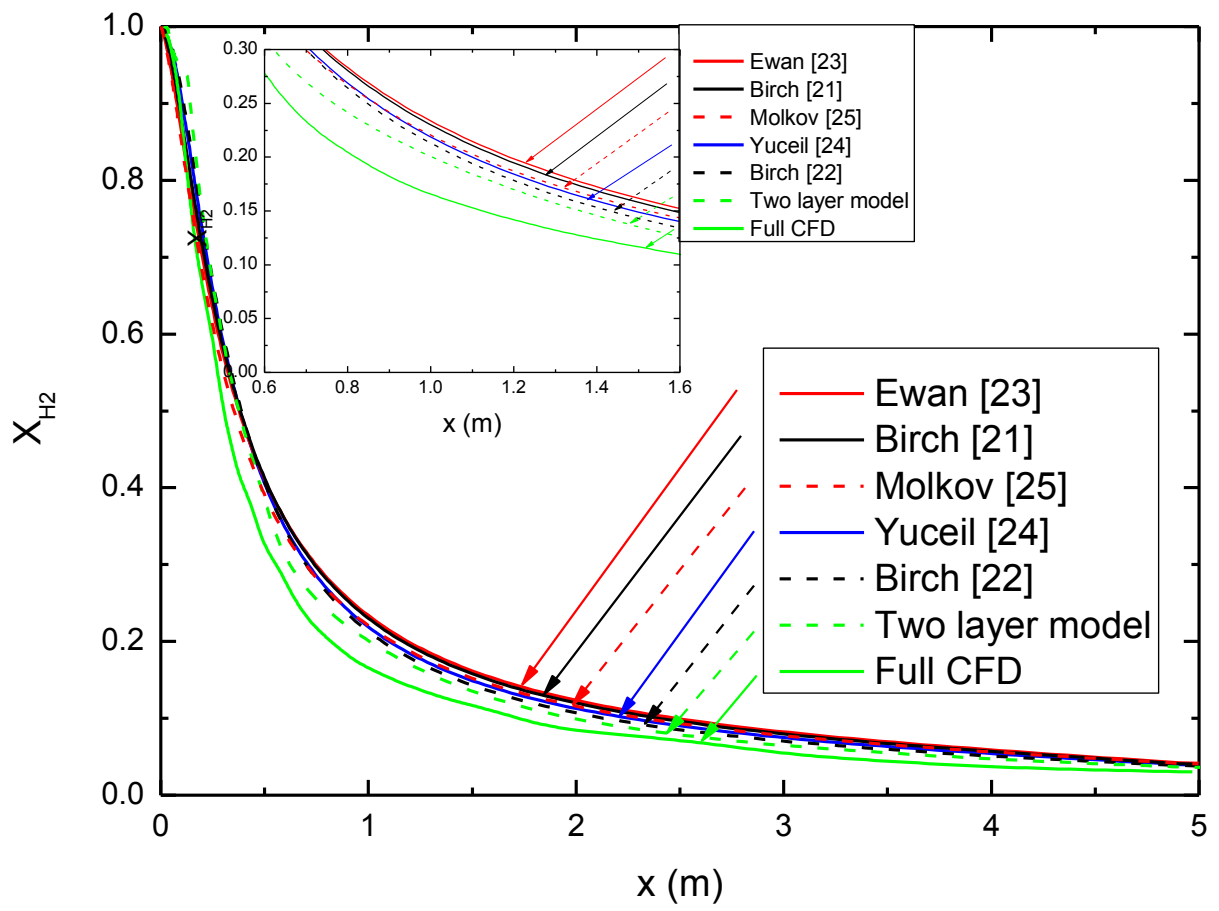

Figure 7. Hydrogen mole fraction centerline concentration variations for $35 \mathrm{MPa}$ tank pressure and a 1 $\mathrm{mm}$ diameter orifice.

The locations of the $4 \%$ lower flammability limit along the centerline are shown in Figure 8 for the same 4 stagnation pressures. Only the Birch et al. [22], Yuceil and Otugen [24] and Molkov et al. [25] notional nozzle models are shown to reduce the clutter in the graph. The measured data points are interpolations of the very sparse data points, so they are somewhat uncertain. The results for $2.6 \mathrm{MPa}$ for helium show the same trends as the results for hydrogen at the higher pressures. As seen in the previous figures, the notional nozzle models overpredict the hydrogen concentrations so they also then overpredict the location of the $4 \%$ lower flammability limit. The other two notional nozzle models predict even longer locations. The two zone model very accurately predicts the measured data for the three cases with experimental data. The full CFD model underpredicts the locations as in Figs. 4-7 since the model is too diffusive. 


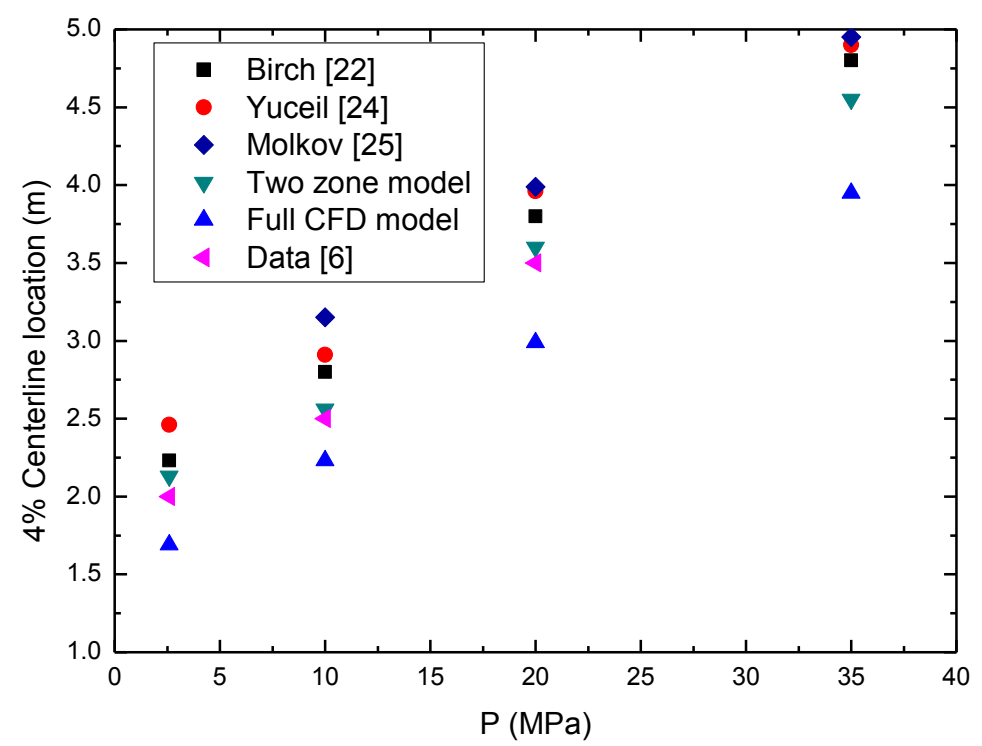

Figure 8 . Locations of the $4 \%$ lower flammability limit location along the centerline for hydrogen jets (2.6 MPa data is for helium).

\subsection{CONCLUSIONS}

A two-layer, reduced order model was developed to describe the flow partitioning in a high pressure underexpanded jet between the core region flowing through the Mach disk and the flow in the slip region that flows around the Mach disk. The hydrogen concentration distributions downstream predicted by this two-layer model were then compared to experimental data and to predictions of four notional nozzle models and CFD models of the flow from a high pressure tank to the far downstream region.

The two-layer model produces much better predictions than the notional nozzle models, especially for higher stagnation pressures. The predictions show that the Birch et al. [22] model consistently gives the best predictions of the measured hydrogen concentrations among the four notional nozzle models, but those predictions are always higher than the data and the predictions of the two-layer model. The Molkov et al. [25] model gives better predictions at higher pressures since it is based on a real gas model. The full CFD model always underpredicts the measured concentrations, which suggests that this model has too much entrainment or too much diffusion perhaps because the turbulent Schmidt number is too small. The use of real gas properties in the CFD models resulted in only slightly lower centerline concentrations that did not significantly reduce the error relative to the experimental data.

The locations of the $4 \%$ lower flammability limit along the centerline are well predicted by the twolayer model. All of the notional nozzle models predicted much longer limits and the full CFD model predicted a shorter distance to the $4 \%$ lower flammability limit than given by the data.

\section{ACKNOWLEDGMENTS}

This research was supported by the National Basic Research Program of China ("973" Project), Grant No. 2011CB706904, by the National Natural Science Foundation of China, Grant No. 51476091, and by the Science Fund for Creative Research Groups of the National Natural Science Foundation of China, Grant No. 51321002. The authors also acknowledge the financial support from China Scholarship Council. The authors also thank the US DOE/EERE Fuel Cell Technologies Office 
for funding and support of this work. Sandia National Laboratories is a multi-program laboratory managed and operated by Sandia Corporation, a wholly owned subsidiary of Lockheed Martin Corporation, for the U.S. Department of Energy's National Nuclear Security Administration under contract DE-AC04-94AL85000.

\section{REFERENCES}

1. EC, 2007. European strategic energy technology plan, Towards a Low Carbon Future, $\operatorname{COM}(2007)$ 723, Brussels, 2007.

2. DoE, 2007. Hydrogen, Fuel Cells \& Infrastructure Technologies Program-Multi-Year Research, Development, and Demonstration Plan. Planned Program Activities for 2005-2015.

3. Gebhart, B., Hilder, D.S. and Kelleher, M. The Diffusion of Turbulent Buoyant Jets, Advances in Heat Transfer, Vol. 16, Academic Press, 1984.

4. Houf, W. and Schefer R., Analytical and Experimental Investigation of Small Scale Unintended Releases of Hydrogen, International Journal of Hydrogen Energy, 33, 2008, pp. 1435-1444.

5. Winter, W.S., Modeling Leaks from Liquid Hydrogen Storage Systems, Sandia National Laboratory, SAND2009-0035.

6. Han S.H., Chang, D. and Kim, J.S., Release Characteristics of Highly Pressurized Hydrogen Through a Small Hole, International Journal of Hydrogen Energy, 38, 2013, pp. 3503-3512.

7. Kuznetsov, M., FZK. Hydrogen distributions tests in free turbulent jet, SBEP V4, Report No.: SBEP V4, 2006

8. Okabayashi, K., Nonaka, T., Sakata, N., Takeno, K., Hirashima, H., Chitose, K., Characteristics of dispersion for leakage of high-pressurized hydrogen gas, Japan Society for Safety Engineering, 44(6), 2005, 391-397.

9. Shirvill, L.C., Roberts, P.T., Butler, C.J., Roberts, T.A., Royle, M., Characterization of the hazards from jet releases of hydrogen, Proceedings of the First International Conference on Hydrogen Safety, Pisa, Italy, 8-10 September 2005.

10. Crist, S., Sherman, P.M. and Glass, R.R., Study of Highly Underexpanded Sonic Jets, AIAA Journal, 4, No. 1, 1966, pp. 68-71.

11. Inman, J.A., Danehy, P.M., Nowak, R.J. and Alberfert, D.W., Fluorescence Imaging Study of Impinging Underexpanded Jets, 46th AIAA Meeting, Reno, 2008.

12. Baraldi, D., Papanikolaou, E., Heitsch, M., Moretto, P., Cant, R. S., Roekaerts, D., Dorofeev, S., Koutchourko, A., Middha, P., Tchouvelev, A.V., Ledin, S., Wen, J., Venetsanos, A. and Molkov, V.V., Gap Analysis of CFD Modelling of Accidental Hydrogen Release and Combustion, JRC Scientific and Technical Report, 2010.

13. Xu, B.P. Zhang, H.P., Wen, J.X., Dembele, S. and Karwatzke, J., Numerical Study of a Highly Under-expanded H2 Jet, First International Conference on Hydrogen Safety, Pisa, Italy, 2005.

14. Chin, C., Li, M., Harkin, C., Rochwerger, T., Chan, L., Ooi, A., Risborg, A. and Soria, J., Investigation of the Flow Structures in Supersonic Free and Impinging Jet Flows, Journal of Fluids Engineering, 135, No. 031202, 2013, pp. 1-12.

15. Papanikolaou, E. and Baraldi, D., Comparison of Modelling Approaches for CFD Simulations of High Pressure Hydrogen Releases, 4th International Conference on Hydrogen Safety, San Francisco, paper 168, 2011.

16. Angers B., Hourri A., Benard P., Tessier P. and Perrin J., Simulations of Hydrogen Releases from High Pressure Storage Systems, WHEC 16, Lyon, France, 2006.

17. Khaksarfard, R. and Paraschivoiu, M., Numerical Investigation of Hydrogen Release from Varying Diameter Exits, 4th International Conference on Hydrogen Safety, San Francisco, paper $159,2011$.

18. Velikorodny, A. and Kudriakov, S., Numerical Study of the Near-field of Highly Underexpanded Turbulent Gas Jets, International Journal of Hydrogen Energy, 37, No. 22, 2012, pp 17390-17399. 
19. Hirsch C. and Tartanville B., Reynolds Averaged Navier-Stokes Modeling for Industrial Applications and Some Challenging Issues, International Journal of Computational Fluid Dynamics, 23, 2009, pp. 295-303.

20. Bonelli, F., Viggiano, A. and Magi, V., A Numerical Analysis of Hydrogen Underexpanded Jets under Real Gas Assumption, Journal of Fluids Engineering, 135, No. 12, 2013, pp. 121101.

21. Birch, A.D., Brown, D.R., Dodson, M.G. and Swaffield, F., The Structure and Concentration Decay of High Pressure Jets of Natural Gas, Combustion Science and Technology, 36, 1984, pp. 249-261.

22. Birch, A.D., Hughes, D.J. and Swaffield, F., Velocity Decay of High Pressure Jets, Combustion Science Technology, 52, 1987, pp. 161-171.

23. Ewan, B.C.R. and Moodie, K., Structure and Velocity Measurements in Underexpanded Jets, Combustion Science and Technology, 45, 1986, pp. 275-288.

24. Yuceil, K.B. and Otugen, M.V., Scaling Parameters for Underexpanded Supersonic Jets, Physics of Fluids, 14, No. 12, 2002, p. 4206.

25. Molkov V.V., Makarov D.V. and Bragin M.V., Physics and Modelling of Underexpanded Jets and Hydrogen Dispersion in Atmosphere, Physics of Extreme States of Matter - 2009, 146-149, Chernogolovka, Russia, 2009.

26. Li, X.F., Christopher, D.M. and Bi, J.L., Release Models for Leaks from High-Pressure Hydrogen Storage Systems, China Science Bulletin, 59, No. 19, 2014, 2302-2308.

27. Li, X.F. and Christopher, D.M., Dispersion of High Pressure Underexpanded Helium Jets into the Atmosphere, 15th International Heat Transfer Conference, Paper 15-9337, Japan, 2014.

28. HySafe, Biennial Report on Hydrogen Safety. Chapter III: Accidental Phenomena and Consequences, 2007, www.hysafe.org.

29. Li, X.F., Bi, J.L. and Christopher, D.M., Comparison of Numerical and Algebraic Models of Low and High Pressure Hydrogen Jet Flows with Ideal and Real Gas Models, 5th International Conference Hydrogen Safety, Paper 186, Brussels, 2013.

30. Tchouvelev A., Hydrogen Implementing Agreement, Task 19 - Hydrogen Safety, Knowledge gaps in hydrogen safety - A white paper, 2008.

31. Glotov, G.F., Local Subsonic Zones in Supersonic Jet Flows, Fluid Dynamics, 33, No. 1, 1998. 117-123.

32. Yuceil, K.B., Otugen, M.V. and Aric, E., Interferometric Rayleigh Scattering and PIV Measurements in the Near-field of Underexpanded Sonic Jets, 41st Aerospace Meeting, Reno, 2003.

33. Ruggles, A.J. and Ekoto, I.W., Ignitability and Mixing of Underexpanded Hydrogen Jets, International Journal of Hydrogen Energy, 37, No. 22, 2011, pp 17549-17560.

34. Veser, A., Kuznetsov, M., Fast, G., Friedrich, A., Kotchourko, N., Stern, G., Schwall, M. and Breitung, W., The Structure and Flame Propagation Regimes in Turbulent Hydrogen Jets, International Journal of Hydrogen Energy, 36, 2011, pp. 2351-2359.

35. Kuznetsov, M., Grune, J., Veser, A., Friedrich, A., Kotchourko, N., Fast, G. and Jordan, T., Optical Observation and Flame Propagation in Turbulent Hydrogen Jets, 14th International Symposium on Flow Visualization, Korea, 2010.

36. Li, X.F., Hecht, E.S, Christopher. D.M., Validation of a reduced-order jet model for subsonic and underexpanded hydrogen jets, International Journal of Hydrogen Energy, 41, 2016, pp. 13481358.

37. Houf, W., Schefer, R., Analytical and experimental investigation of small-scale unintended releases of hydrogen International Journal of Hydrogen Energy, 33, 2008, pp. 1435-1444.

38. NASA Isentropic flow equations, 2015, www.grc.nasa.gov/www/k-12/airplane/isentrop.html

39. NASA Normal shock wave equations, 2014, www.grc.nasa.gov/www/BGH/normal.html

40. El-Amin, M.F. and Sun, S., Horizontal H2-air Turbulent Buoyant Jet Resulting from Hydrogen Leakage, International Journal of Hydrogen Energy, 37, 2012, 3949-3957. 